\title{
MICROSTRUCTURE INVESTIGATION OF STRIP-CAST Nd-Fe-B ALLOY
}

\author{
${ }^{1}$ Kateřina SKOTNICOVÁ, ${ }^{2}$ Gennady S. BURKHANOV, ${ }^{1}$ Tomáš ČEGAN, \\ ${ }^{2}$ Natalia B. KOLCHUGINA, ${ }^{3}$ Alexander A. LUKIN, ${ }^{1}$ Jan JUŘICA, ${ }^{2}$ Pavel A. PROKOF'EV, \\ ${ }^{2}$ Nikolay A. DORMIDONTOV, ${ }^{1}$ Miroslav KURSA, ${ }^{1}$ Ondřej ŽIVOTSKÝ, ${ }^{1}$ Bedřich SMETANA \\ ${ }^{1}$ VSB-Technical University of Ostrava, Regional materials science and technology centre, Ostrava, Czech \\ Republic, EU, katerina.skotnicova@vsb.cz \\ ${ }^{2}$ Baikov Institute of Metallurgy and Materials Science, Russian Academy of Sciences, Moscow, Russian \\ Federation \\ 3JSC SPETSMAGNIT", Moscow, Russian Federation
}

https://doi.org/10.37904/metal.2019.762

\begin{abstract}
The microstructure of initial Nd-Fe-B alloy has the substantial effect on the processing and the hysteretic properties of sintered Nd-Fe-B-based magnets. This work is aimed at the structural characterization of the strip-cast Nd-Fe-B alloy, which will be used as the matrix alloy for the preparation of magnets with variable set of functional parameters via the application of REM hydrides or hydrogenated REM compounds added to the powder mixture and using processes of grain boundary diffusion and grain boundary structuring. The microstructure, phase composition and distribution of $\mathrm{Nd}$ in the structural components of the strip-cast alloy were investigated by SEM/EDX, DTA and XRD methods. The nucleation region in the contact area between the cooling wheel and melt and radially grown $\mathrm{Nd}_{2} \mathrm{Fe}_{14} \mathrm{~B}$ dendritic structure was observed. Individual dendrite arms are characterized by different crystal orientations and a thickness of 2 to $5 \mu \mathrm{m}$. In the interdendritic regions, the $\mathrm{R}$-rich phase with a variable ratio of $\mathrm{Nd} / \mathrm{Fe}$ is present. In this region, the $\mathrm{NdFe}_{4} \mathrm{~B}_{4}$ compound was also identified as the minority phase. The $\mathrm{X}$-ray elemental map showed the increased boron content in this phase. Major diffraction peaks in the XRD patterns could be indexed to either $\mathrm{Nd}_{2} \mathrm{Fe}_{14} \mathrm{~B}$ or $\mathrm{Nd}$-based phases. According to DTA data obtaining upon heating, the first peak is recorded in the temperature range of 693 to $731^{\circ} \mathrm{C}$ which is probably related to the decomposition of $\mathrm{NdFe}_{4} \mathrm{~B}_{4}$ phase. Other peak in a range of from 980 to $1061{ }^{\circ} \mathrm{C}$ is related to the melting of $\mathrm{Nd}$-rich phases.
\end{abstract}

Keywords: Nd-Fe-B alloy, strip casting, permanent magnet, microstructure, magnetic properties.

\section{INTRODUCTION}

Sintered Nd-Fe-B-based magnets are demanded for clean energy applications, in particular, for hybrid and electric vehicles. The usage of the magnets has been increased recently and also will be increased in the future due to the consideration for the environmental issues [1-3]. For the production of sintered Nd-Fe-B magnets by powder technology, the microstructure of initial alloy has the substantial effect on the processing and the hysteretic properties of magnet. The strip casting (SC) is the convenient method for the preparation of $\mathrm{Nd}-\mathrm{Fe}-\mathrm{B}$ alloy with the fine-grained structure and uniform distribution of the Nd-rich phase. The main advantages of strip casting include the ability to achieve a higher alignment coefficient, optimum rare-earth metals content, high fraction of the hard magnetic phase and high permanent magnetic properties of sintered magnets prepared from strip-cast alloys [4-5]. Conventional casting techniques show the formation of a high quantity of precipitated $\alpha-\mathrm{Fe}$, which leads the decrease in powder alignment and the formation of large Nd-rich regions that are very sensitive to oxidation. The $\alpha$-Fe is formed according to the pseudo-binary Fe-(Nd,B) phase diagram, with $\mathrm{Nd}: \mathrm{B} 52: 1$, where the solidification path passes through a region ( $\mathrm{Liq}+\mathrm{Fe})$, and Fe particles are formed as the primary solidified phase [6-7]. Due to the high cooling rate during the solidification in the strip casting process, the formation of $\alpha$-Fe dendrites and undistributed $\mathrm{Nd}$-rich phase are prevented and the SC 
alloys show a micron-sized lamellar structure composed of the $\mathrm{Nd}_{2} \mathrm{Fe}_{14} \mathrm{~B}$ and $\mathrm{Nd}$-rich phases. This lamellar structure is effective for forming the uniform distribution of Nd-rich phase and controlling the grain size [4-7]. The strip-cast alloy is then submitted to the hydrogen decrepitation and subsequent jet milling to produce the powder mixture with an average particle size of 3 to $5 \mu \mathrm{m}$. This powder material can be mixed with the additional alloying components during the mechanical activation. After the pressing of powder in the presence of external magnetic field, the compacts are sintered and heat treated.

This paper deals with the preparation of the strip-cast Nd-Fe-B alloy with the near-stoichiometric composition, which will be used as the matrix alloy for the preparation of magnets with variable set of functional parameters via the application of REM hydrides or hydrogenated REM compounds added to the powder mixture and using processes of grain boundary diffusion and grain boundary structuring. The microstructure, phase transformations and magnetic characteristics were investigated in detail.

\section{EXPERIMENTAL}

The base alloy having the composition (wt\%) Nd-32.0, B-1.0, Al-0.3, Fe-balance was prepared using vacuum induction melting. The crucible was filled with the pure metals ( $\mathrm{Nd}, \mathrm{Pr} \geq 99.5 \%, \mathrm{Fe} \geq 99.9 \%$ ) and ferro-boron (Fe80B20, carbothermic type) and placed into the chamber of furnace, which was evacuated to a pressure of $5 \mathrm{~Pa}$. Before the melting process, the chamber was filled with argon (99.999\% purity) to a pressure of $20 \mathrm{kPa}$. After melting the material, the melt was poured into a pre-heated tundish, where gravity flowed through the boron-nitride nozzle onto a cooled rotating wheel - see Figure 1. The surface velocity was maintained at a speed of $1.5 \mathrm{~m} / \mathrm{s}$. The strips obtained were 0.4 to $0.7 \mathrm{~mm}$ in thickness and 10 to $15 \mathrm{~mm}$ in width. The samples of strips in the longitudinal- and cross-section were subjected to the metallographic analysis, when the diamond pastes were used for the polishing to a mirror-like surface. The surface of strips was also investigated in ascast state.

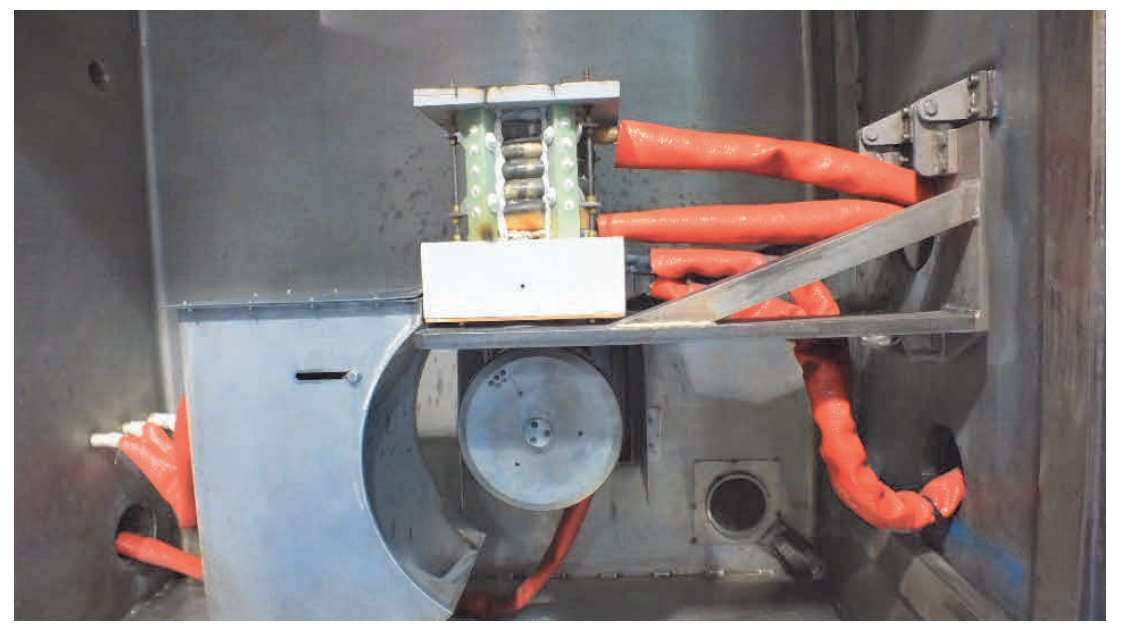

Figure 1 The strip casting equipment for the preparation of Nd-Fe-B magnetic materials

The FEI QUANTA 450 FEG high-resolution field emission gun scanning electron microscope (SEM) equipped with an EDS microanalyzer was used to investigate the structure, chemical composition and the distribution of components ( $\mathrm{x}$-ray mapping) in the strip-cast alloy. The hydrogen and oxygen contents were determined using an ONH - 2000 ELTRA analyzer. The phase constitution was detected by X-ray diffraction (XRD) using a Bruker Advance D8 diffractometer equipped with a linear semiconductor detector LynxEye and a SOL-XE energy-dispersive detector. The phase transformation in the strip-cast alloys during heating in the temperature range from 20 to $1500{ }^{\circ} \mathrm{C}$ was studied by the differential thermal analysis (using a Setaram Setsys Evo 1750 installation). Thermo-magnetic analysis (TMA) was carried out in the temperature range from 20 to $1000{ }^{\circ} \mathrm{C}$ in the magnetic field of $159 \mathrm{kA} / \mathrm{m}$ using a Microsense EZ9 vibrating-sample magnetometer (VSM). 


\section{RESULTS AND DISCUSSION}

\subsection{Metallographic analysis of strip-cast Nd-Fe- alloy}

The petal-shaped microstructure of strip on its chilled surface (contact surface), which was incontact with the cooling wheel, and the very fine microstructure on its free surface is shown in Figure 2. The petal-shaped grains at the contact surface are surrounded by Nd-rich phase with relative large thickness. In contrast, the $\mathrm{Nd}$-rich phase at the free surface is distributed more uniformly. The nucleation region in the contact area between the cooling wheel and melt and radially grown $\mathrm{Nd}_{2} \mathrm{Fe}_{14} \mathrm{~B}$ dendritic structure can be observed in Figure 2a. Individual dendrites arms are characterized by different crystal orientations and a thickness about 2 to $5 \mu \mathrm{m}$ - see Figure 3 .

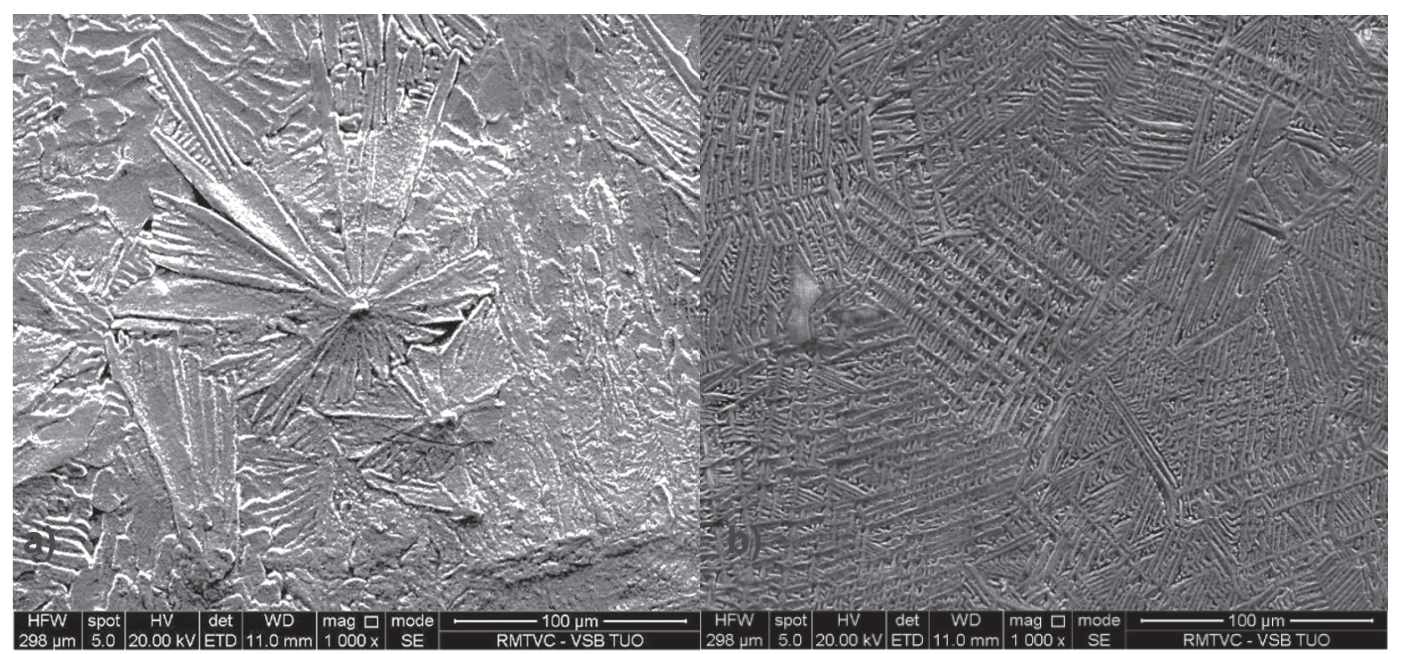

Figure 2 The microstructure of (a) contact and (b) free surfaces of strip-cast Nd-Fe-B alloy(as-cast state).

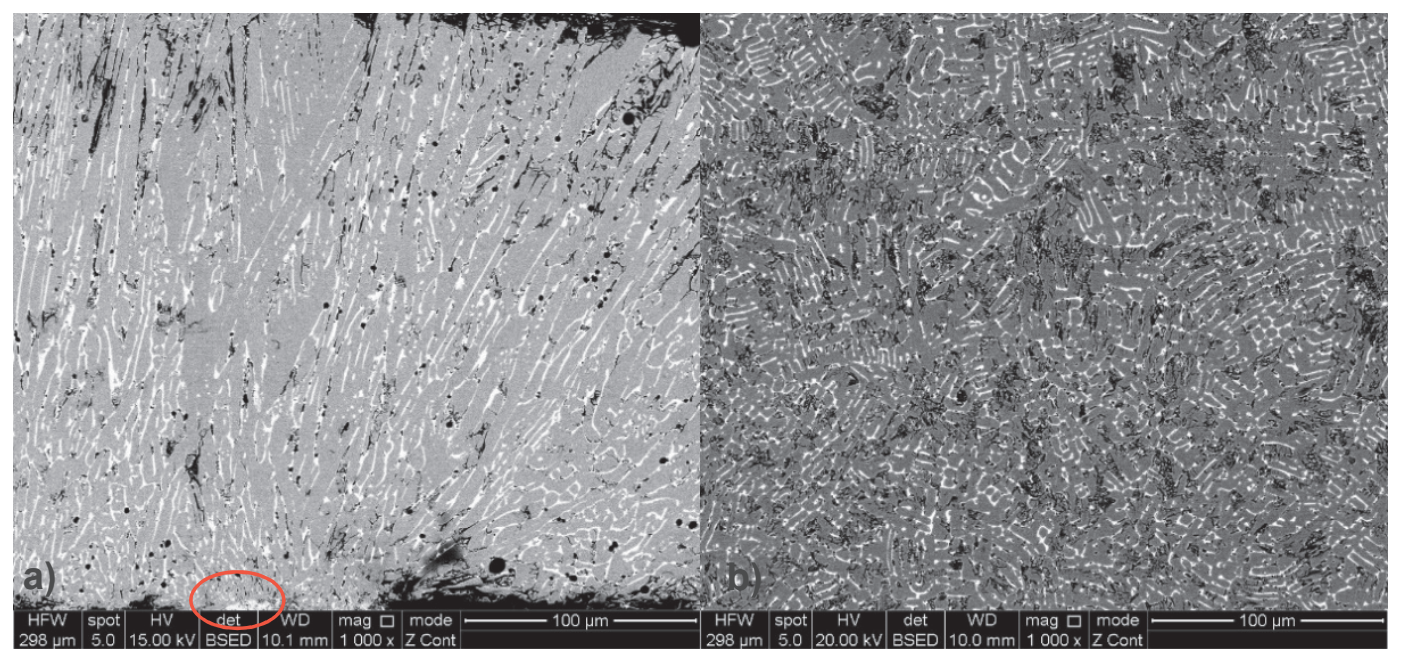

Figure 3 The microstructure of strip-cast Nd-Fe-B alloy in (a) cross and (b) longitudinal section near the contact surface $(b)$

The results of the local electron microprobe analysis of the found phases are given in Table 1; the values averaged for three measurements are given for phases 1, 3 and 4 . The stoichiometric composition of dendrites is close to that of the $\mathrm{Nd}_{2} \mathrm{Fe}_{14} \mathrm{~B}$ phase (phase 1 in Table 1). In the interdendritic regions, the Nd-rich phase with a variable ratio of $\mathrm{Nd} / \mathrm{Fe}$ is present. In this region, the $\mathrm{NdFe}_{4} \mathrm{~B}_{4}$ compounds (B-rich phase) was identified as the minority phase (phase 3 ). The white elliptic area at the central bottom in Figure $\mathbf{3 a}$, at the periphery of 
which dendrites grow outwards in all directions, was identified as possible Laves phase $\mathrm{RFe}_{2}$ (phase 4 in Table 1). The atomic ratio of $\mathrm{Nd}$ :Fe of this phase corresponds with $\sim 1: 2$. But it is not clear whether the $\mathrm{NdFe}_{2}$ phase is a stable compound. The total oxygen content was determined to be $288 \mathrm{ppm}$.

Table 1 The chemical composition of strip-cast Nd-Fe-B alloy and marking of analyzed phases

\begin{tabular}{|l|c|c|c|c|c|c|}
\hline \multirow{2}{*}{$\begin{array}{c}\text { Phase I } \\
\text { Element }\end{array}$} & \multicolumn{2}{|c|}{ Alk } & \multicolumn{2}{c|}{ Nd } & \multicolumn{2}{c|}{ Fe } \\
\cline { 2 - 7 } & (wt\%) & (at\%) & (wt\%) & (at\%) & (wt\%) & (at\%) \\
\hline Area & 0.1 & 0.2 & 36.5 & 18.2 & 63.4 & 81.6 \\
\hline Phase_1 & 0.1 & 0.3 & 30.1 & 14.2 & 69.8 & 85.5 \\
\hline Phase_2_1 & 0.0 & 0.0 & 97.4 & 93.5 & 2.6 & 6.6 \\
\hline Phase_2_2 & 0.5 & 1.9 & 78.3 & 57.7 & 21.2 & 40.3 \\
\hline Phase_2_3 & 0.0 & 0.0 & 94.7 & 87.4 & 5.3 & 12.7 \\
\hline Phase_3 & 0.1 & 0.2 & 44.5 & 23.7 & 55.4 & 76.2 \\
\hline Phase_4 & 0.0 & 0.1 & 57.8 & 34.6 & 42.2 & 65.3 \\
\hline
\end{tabular}

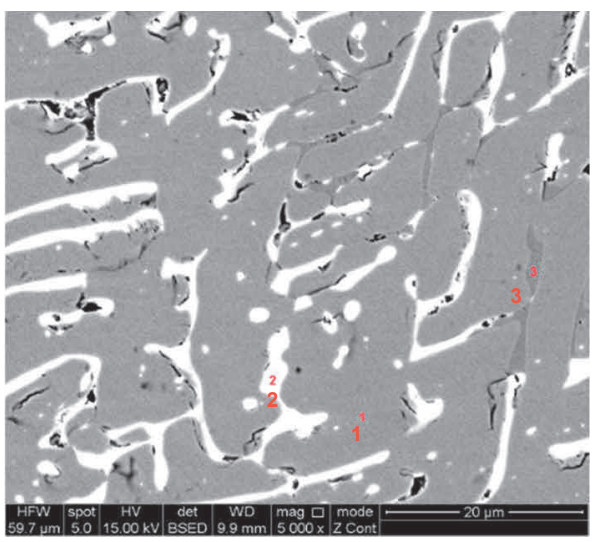

Figure 4 shows the XRD patterns obtained from the strip-cast Nd-Fe-B alloy. Each peak could be indexed to either $\mathrm{Nd}_{2} \mathrm{Fe}_{14} \mathrm{~B}$ or $\mathrm{Nd}$ phases. Other phases revealed using SEM were not identified probably due to their low volume fraction in the sample.

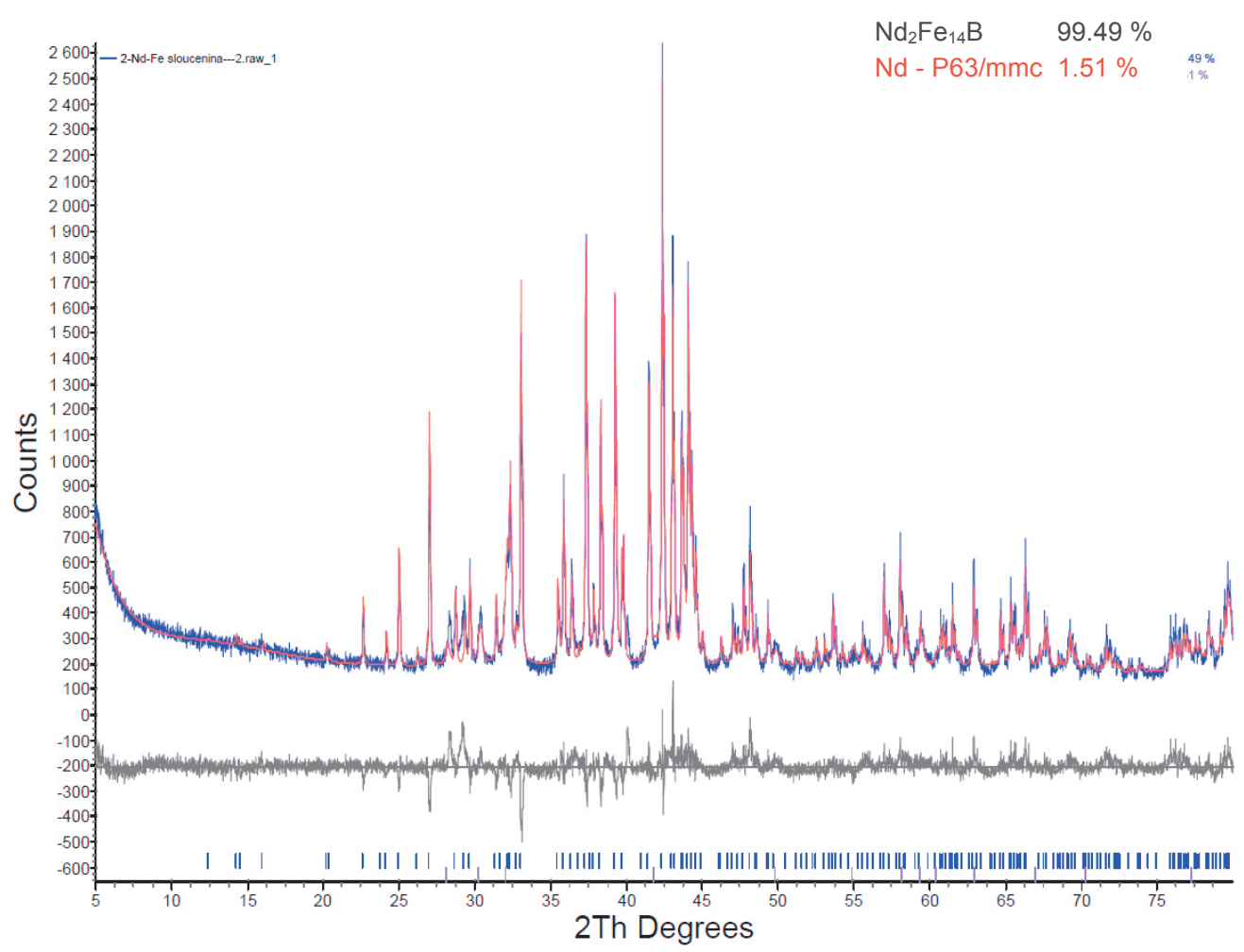

Figure $4 \mathrm{XRD}$ patterns taken for the strip-cast alloy with reflections corresponding to $\mathrm{Nd}_{2} \mathrm{Fe}_{14} \mathrm{~B}$ and $\mathrm{Nd}$ phases

The distribution of individual components of strip-cast alloy was studied using $\mathrm{x}$-ray mapping - see Figure 5 . The uniform Nd, Al and B distribution within 2-14-1 grains was observed. It can be seen the higher content of boron in the intergranular phase which is considered to be $\mathrm{NdFe}_{4} \mathrm{~B}_{4}$ (B-rich phase, red circle in Figure 5 ). 

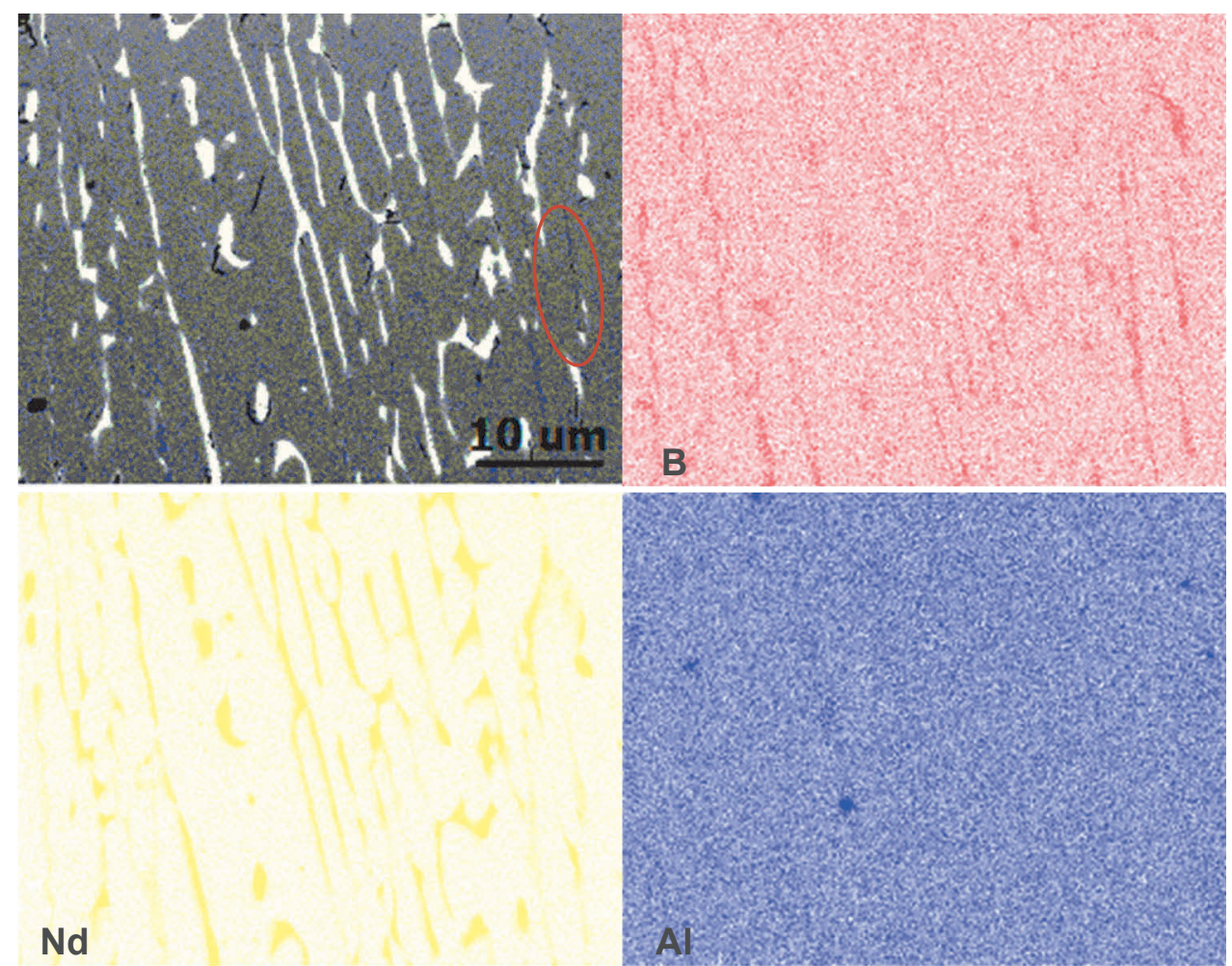

Figure $5 \mathrm{X}$-ray mapping of $\mathrm{B}, \mathrm{Nd}$ and $\mathrm{Al}$ in the matrix grains and $\mathrm{Nd}$-rich phases of $\mathrm{Nd}-\mathrm{Fe}-\mathrm{B}$ strip-cast alloy

For the determination of suitable conditions of sintering and heat treatment of sintered magnet, the phase composition of this alloy was also studied by DTA during heating. According to obtained results in Figure 6 and literature data [8], the first peak at $309^{\circ} \mathrm{C}$ corresponds with the Curie temperature of the ferromagnetic $\mathrm{Nd}_{2} \mathrm{Fe}_{14} \mathrm{~B}$ phase.

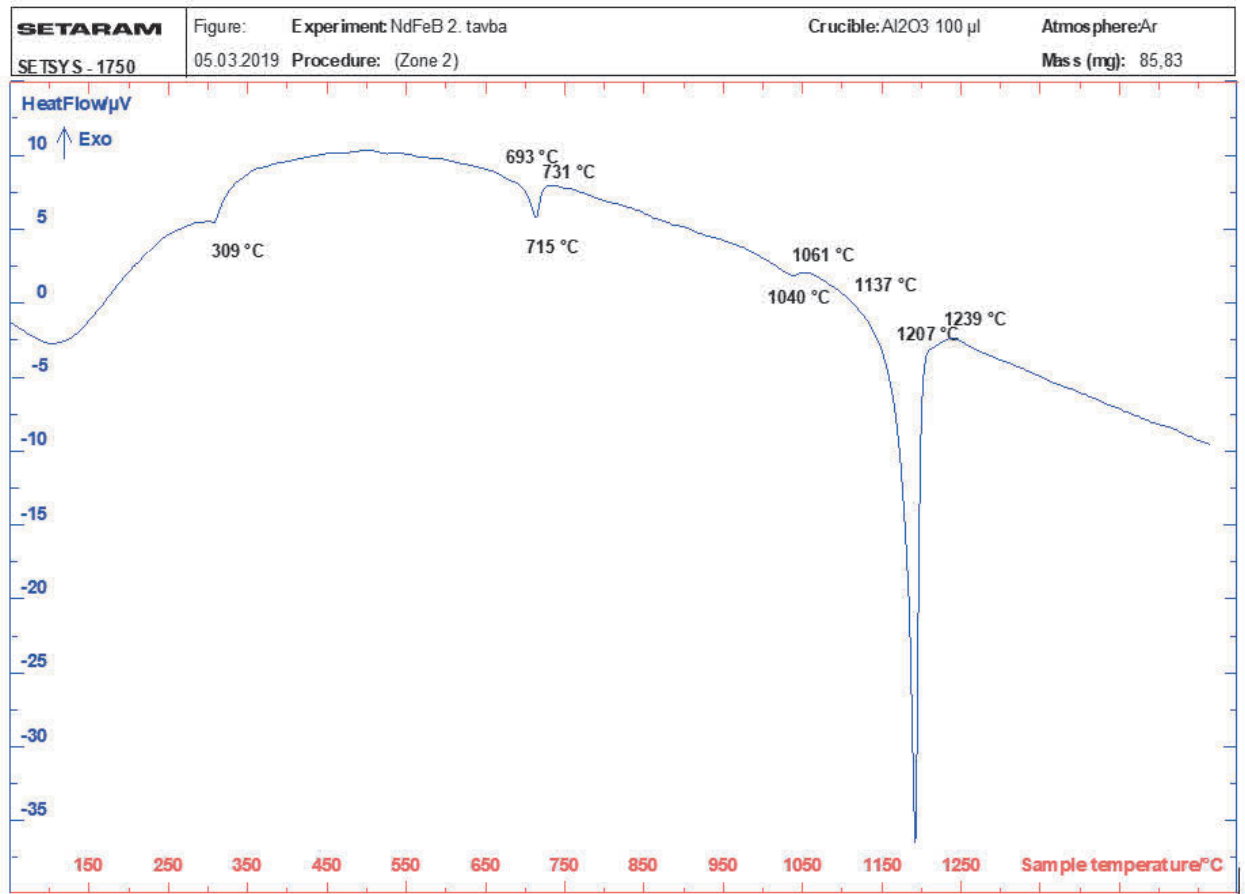

Figure 6 DTA curvefor thestip-cast Nd-Fe-B alloy measured during heating 
The other peak was recorded in the temperature range of 693 to $731{ }^{\circ} \mathrm{C}$, which is probably related to the decomposition of $\mathrm{NdFe}_{4} \mathrm{~B}_{4}$ phase. Other peak from 1040 to $1061^{\circ} \mathrm{C}$ corresponds to the melting of $\mathrm{Nd}$-rich phase components. The peak in the temperature range from 1137 to $1207{ }^{\circ} \mathrm{C}$ agrees with the reaction $L+\mathrm{Nd}_{2} \mathrm{Fe}_{14} B \Rightarrow L$.

The thermo-magnetic curve is shown in Figure 7, where two peaks corresponding to $\mathrm{Nd}_{2} \mathrm{Fe}_{14} \mathrm{~B}$ and $\alpha$-Fe magnetic phase ssuccessively appear (marked with arrows in Figure 7). The Curie temperatures of these phases were measured to be about 300 and $765^{\circ} \mathrm{C}$, respectively. The soft magnetic phase plays a negative role on the intrinsic coercivity as well as the magnetic energy product and can be eliminated by the heat treatment. It should be note that $\alpha-F e$ phase was not detected

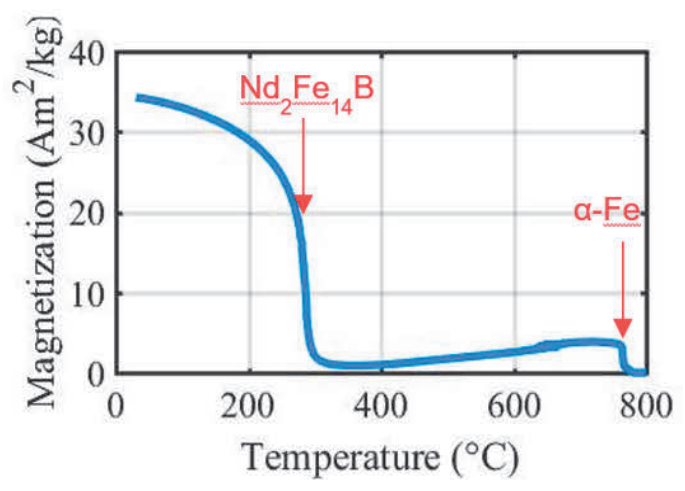

Figure 7 Thermo-magnetic curve of strip-cast Nd-Fe-B alloy. The Curie temperatures of $\mathrm{Nd}_{2} \mathrm{Fe}_{14} \mathrm{~B}$ and $\alpha-\mathrm{Fe}$ phases are marked with arrows by SEM/EDX, DTA or XRD methods used for the investigation of thephase compositionof the strip. Itis therefore assumed that its volume fraction is very low.

\section{ACKNOWLEDGEMENTS}

This paper was created within the project LTARF18031 "Development of physico-chemical and engineering foundations for the initiation of innovative resources-economy technology of highpower and high-coercivity (Nd,R)-Fe-B (R = Pr, Tb, Dy, Ho) low-REM permanent magnets" and within the project No. 14.616.21.0093 (the unique identification number RFMEFI61618X0093).

\section{REFERENCES}

[1] MITCHELL, I.V., COEY, J.M., GIVORD, D., HARRIS, I.R. and HANITSCH, R. ed. Concerted European Action on Magnets (CEAM). Essex: Elsevier Science Publishers LTD, 2012. 928 p.

[2] GUTFLEISCH, O., WILLARD, M.A., BRUCK, E., CHEN, C.H., SANKAR, S.G. and LIU, J.P. Magnetic materials and devices for the $21^{\text {st }}$ century: Stronger, lighter, and more energy efficient. Advanced Materials. 2011. vol. 23, no. 7, pp. 821-842.

[3] BURKHANOV, G.S., LUKIN, A.A., KOLCHUGINA, N.B., KOSHKID'KO, Y.S., CWIK, J., SKOTNICOVÁ, K., ČEGAN, T., PROKOF'EV, P.A., DRULIS, H. and HACKEMER, A. Structure and phase composition of Tb3Co0.6Cu0.4 alloys for efficient additions to Nd-Fe-B sintered magnets. In METAL 2017: 26th International Conference on Metallurgy and Materials. Ostrava: TANGER, 2017. pp. 1775-1781.

[4] YAMAMOTO, K., MATSUURA, M. and SUGIMOTO, S. Microstructure formation in strip-cast RE-Fe-B alloys for magnets. Metallurgical and Materials Transactions A. 2017. vol. 48, no. 7, pp. 3482-3489.

[5] ZHU, M., FANG, Y., GUO, Y., LIA, W., HAN, B. Study of magnetic microstructures of Nd-Fe-B casting strips by using magnetic force microscope. Journal of Magnetism and Magnetic Materials. 2014, vol. 282, pp. 180-185.

[6] YAMAMOTO, K. and MURAKAMI, R. Microstructural Analysis of NdFeB Ternary Alloy for Magnets Fabricated Using a Strip-Casting Method. Materials Transactions. 2016. vol. 57, no. 8, pp. 1266-1271.

[7] VASILENKO, D.Yu., SHITOV, A.V., VLASYUGA, A.V., POPOV, A.G., KUDREVATYKH, N.V. and PECHISHCHEVA, N.V. Microstructure and properties of Nd-Fe-B alloys produced by strip casting and of permanent magnets fabricated from them. Metal Science and Heat Treatment. 2015. vol. 56, no. 11-12, pp. 585590.

[8] YAMAMOTO, K., IRIE, T. and TAKEUCHI, M. Influence of cooling rate on constituent phases and distribution of elements in (Nd,Dy)-Fe-B magnet alloys. Journal of the Japan Society of Powder and Powder Metallurgy. 2016. vol. 63 , no. 7 , pp. 630-635. 